\title{
С.В. ЛОГИНОВ
}

\section{ЭКСПЕРИМЕНТАЛЬНОЕ УСТАНОВЛЕНИЕ СКЕЙЛИНГА НАПРЯЖЕНИЯ ПЛАЗМЕННОГО ПРЕРЫВАТЕЛЯ ТОКА}

\begin{abstract}
Приведено теоретическое обобщение скейлинга развиваемого на прерывателе напряжения в зависимости от тока проводимости прерывателя. Дана экспериментальная верификация скейлинга на мегаамперной установке ГИТ-4. Показано, что зависимость напряжения на прерывателе от тока проводимости имеет немонотонный характер: участок нарастания напряжения при токе проводимости прерывателя менее $\sim 1$ МА сменяется снижением напряжения при дальнейшем увеличении тока более $\sim 1$ МА. Это обусловлено изменением режима работы прерывателя с эрозионного рассасывания плазмы на режим сгребания плазмы давлением нарастающего магнитного поля. В результате мощность развиваемого на прерывателе импульса ограничивается уровнем достигаемого напряжения при токе $~ 1$ МА. Обнаруженный скейлинг напряжения подтверждается также аппроксимацией экспериментальных данных мегаамперных установок HAWK и модуля DECADE.
\end{abstract}

Ключевые слова: мегаамперный импульсный генератор, плазменный прерыватель тока, скейлинги тока и напряжения.

\section{Введение}

Для создания тераваттных радиационных источников на исходе XX века интенсивно верифицировалась технология получения мощных импульсов тока в излучающей нагрузке в схеме с промежуточным индуктивным накопителем и плазменным прерывателем. Привлекательность применения прерывателя обусловлена его чрезвычайной простотой в техническом отношении. Он представляет собой отрезок вакуумного коаксиала, заполненный предварительно инжектированной полностью ионизованной плазмой. В стадии проводимости плазменная перемычка позволяет зарядить индуктивный накопитель до некоторого тока, при котором сопротивление прерывателя резко нарастает, обеспечивая генерацию импульса высокого напряжения. Вместе с тем из сравнительного анализа экспериментов с нано- и микросекундным временем проводимости прерывателя следует, что увеличение энергии первичного накопителя с соответствующим увеличением времени проводимости прерывателя приводит к снижению развиваемой прерывателем мощности импульса. Эта негативная тенденция детерминирована изменением механизма транспорта магнитного поля через плазму прерывателя, в результате которого меняется функциональная зависимость возникающего на прерывателе напряжения от величины обрываемого тока.

Теоретический анализ происходящих в плазме прерывателе процессов выявил немонотонную зависимость развиваемого на прерывателе напряжения $U_{s}$ от плотности плазмы $n$ и/или тока проводимости $I_{c}$ [1]. Это иллюстрируется рис. 1 , дающим обобщение скейлинга $U_{s}\left(I_{c}\right)$. В преры-

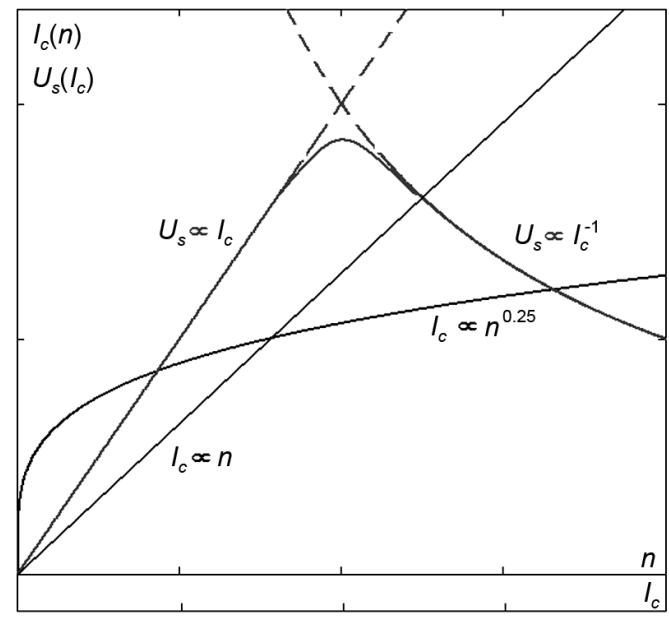

Рис. 1. Обобщение скейлинга напряжения вателе с низкой концентрацией плазмы ток проводимости $I_{c}=\left(m_{i} / Z m\right)^{1 / 2} 2 \pi r_{c} l Z e n_{i} v_{d} \propto n$, где $m_{i}$ и $m-$ масса иона и электрона; $Z$ и $e$ - заряд иона и электрона; $n_{i}=n / Z$ - плотность ионов в однородной перемычке протяженностью $l ; v_{d}$ - скорость дрейфа ионов на катод с радиусом $r_{c}$. В области выполнения скейлинга возникающее на прерывателе напряжение линейно зависит от достигаемого к моменту обрыва тока проводимости. При повышении плотности плазмы ток проводимости $I_{c}=\left(12 \pi n_{i} m_{i} c^{2}\right)^{1 / 4}\left(\dot{I}_{c} l\right)^{1 / 2} \propto n^{1 / 4}$, где $\dot{I}$ - скорость нарастания тока в прерывателе, $c$ скорость света. В этом случае пик напряжения на прерывателе обратно пропорционален величине тока проводимости $I_{c}$. 
Уважаемые читатели!

Доступ к полнотекстовой версии журнала
«Известия высших учебных заведений. Физика» осуществляется на платформе Научной электронной библиотеки eLIBRARY.RU на платной основе:

https://elibrary.ru/contents.asp?titleid=7725 